\title{
RANCANGAN SOLUSI PENGELOLAAN SAMPAH DENGAN KONSEP FOCUS GROUP DISCUSSION (FGD) PENTA HELIX DI KABUPATEN GARUT
}

\author{
Dini Turipanam Alamanda \\ Fakultas Ekonomi, Universitas Garut, Jl Samarang 52, Garut, Indonesia \\ alamanda.dini.2017@gmail.com

\section{Hadum Hadiansyah} \\ Fakultas Ilmu Sosial dan Ilmu Politik, Universitas Garut, Garut, Indonesia \\ hadum1998@gmail.com \\ Abdullah Ramdhani \\ Fakultas Ilmu Sosial dan Ilmu Politik, Universitas Garut, Garut, Indonesia \\ aramdhani@fisip.uniga.ac.id
}

\begin{abstract}
The waste problem in Garut Regency was entering an emergency and alarming stage. The situation has mobilized various elements, namely academics, entrepreneurs, communities, government and the media to take strategic steps together in overcoming the problem of waste. Garut University, especially Faculty of Social and Political Sciences (FISIP), became the initiator of the focus group discussion (FGD) agenda which subsequently developed into the Penta helix Garut Free Waste Movement. The purpose of this study was to map the solution steps taken by the Penta helix team based on the results of the FGD. This research was a qualitative type using FGD method. The FGD was attended by 28 participants consisting of 3 academic representatives, 7 company representatives, 6 community representatives, 10 government representatives, and 2 media representatives. Triangulation was carried out on the initiator's side by testing the dependability and confirmability. The results showed that there were 7 strategic issues namely technology, processing, education, economics, institutions, policies and coordination that needed to be further discussed through further FGDs. All elements were expected to continue to communicate and collaborate and could complete the discussion of the 7 issues to be used as a solution proposal to the government of Garut Regency, therefore, it could be used as material for policy formulation to solve the waste problem.
\end{abstract}

Keywords: Waste Solution, Penta helix, Public Policy, City Management, Social Issue.

Submitted: July 2, 2020

Reviewed: November 7, 2020

Published: November 24, 2020

How to Cite: Alamanda, Dini Turipanam, Hadum Adiansyah, dan Abdullah Ramdhani. 2020. Rancangan Solusi Pengelolaan Sampah dengan Konsep Focus Group Discussion (FGD) Penta Helix di Kabupaten Garut. Vol 4 (2): pp. 226-240. DOI: https://doi.org/10.24036/jess.v4i2

\section{Pendahuluan}

Tempat Pembuangan Akhir (TPA) Pasir Bajing seluas 14 Ha di Desa Sukaraja, Kecamatan Banyuresmi, Kabupaten Garut saat ini sudah tidak bisa menampung sampah. Selain itu akses jalan yang buruk dan cara pengelolaan pembuangan terbuka (open dumping) menyebabkan pengangkutan sampah ke TPA Pasir Bajing 
mengalami perlambatan. Tumpukan sampah sering terjadi di beberapa kecamatan yakni Garut Kota, Tarogong Kaler, Tarogong Kidul, Banyuresmi, Leles, dan Kadungora. Selain mengganggu estetika, penumpukan sampah juga rentan dengan munculnya berbagai penyakit.

Kepala Seksi Pengembangan Teknologi Pengolahan Sampah Dinas Lingkungan Hidup (DLH) Kabupaten Garut mengatakan sampah di Kabupaten Garut diperkirakan mencapai 1.000 ton per hari, dimana 500 ton kubiknya berasal dari daerah perkotaan. Dari timbunan sampah 483 ton/ hari hanya 212.53 ton yang dapat terangkut dari 15 kecamatan atau tingkat pelayanan persampahan (perkotaan) Kabupaten Garut baru mencapai $43.98 \%$.

Undang-undang Nomor 18 Tahun 2008 Pasal 44 tentang Pengelolaan Sampah menekankan bahwa pemerintah daerah sudah harus menutup tempat pemrosesan akhir sampah yang menggunakan sistem pembuangan terbuka paling lama 5 tahun sejak undang-undang itu diberlakukan. Sehingga seharusnya, Pemkab Garut sudah menutup dan mengganti sistem pemrosesan akhir sampah dengan sistem yang lebih baik seperti sistem sanitary landfill. Selain kondisi TPA, cara pengelolaan, faktor lainnya adalah sumber daya manusia (SDM), pengelolaan sampah yang masih dalam skala kecil, penggunaan teknologi pengelolaan sampah yang masih sederhana, serta program-program yang direncanakan dan dilaksanakan oleh Pemkab Garut belum berdampak signifikan.

DLH Kabupaten Garut telah melakukan berbagai upaya untuk mengatasi permasalahan sampah. Upaya yang dilakukan diantaranya dengan menyediakan tempat penampungan sementara (TPS) dan tempat pemrosesan akhir (TPA), serta mengangkut sampah dari TPS ke TPA dengan kendaraan pengangkut sampah, membuat regulasi dan lain sebagainya. Pengelolaan sampah di Kabupaten Garut tidak hanya dilakukan oleh DLH, warga Desa Sukakarya berupaya mengolah sampah plastik menjadi tas, dompet, sandal, kap lampu, dan barang-barang lainnya. Kerajinan ini sudah diminati oleh pasar internasional seperti negara Australia yang memesan matras yang terbuat dari kantong plastik bekas (Info Publik, 2016). Komunitas World Cleanup Day (WCD) pernah melakukan gerakan memungut sampah yang dilaksanakan di Kecamatan Garut Kota yang diikuti oleh 52 Komunitas yang terdiri dari Komunitas Ojek Online, Komunitas Mahasiswa, Himpunan Mahasiswa Islam, Organisasi Sekolah, Komunitas Motor, Ormas dan Umum. Kegiatan yang dilakukan bertujuan untuk meningkatkan kesadaran masyarakat akan pentingnya menjaga lingkungan yang beresih dan nyaman dari sampah (Kania, 2020).

Fakultas Pertanian (Faperta) Universitas Garut juga telah melakukan pemanfaatan sampah menjadi kompos untuk sawah petani, sampah yang dijadikan bahan dasar adalah sampah pasar. Pengusaha pengelolaan sampah juga telah melakukan upaya mengatasi masalah sampah yang ada, salah satunya yang dilakukan oleh Bank Sampah Hade Jaya yang menampung berbagai jenis sampah, seperti sampah dus, plastik, besi, dan lainnya untuk selanjutnya diolah dan dijual kembali ke berbagai industry di Jakarta dan Tangerang. Beberapa news online nasional juga berkontribusi dalam penyebaran informasi pengelolaan sampah di Kabupaten Garut. Sayangnya, gerakan-gerakan pengelolaan sampah tersebut di atas masih bersifat bebas satu sama lain dan belum terintegrasi sehingga belum bisa 
mengatasi krisis sampah di Kabupaten Garut. Mengamati hal tersebut, Ikeu Kania dari Universitas Garut dibantu oleh Cecep Ernanto dari LKP Holistika Institute mengundang para pemerhati, penggiat dan pengusaha sampah untuk bersama-sama mencari solusi krisis sampah di Kabupaten Garut melalui kegiatan FGD.

Berdasarkan latar belakang di atas, tujuan penelitian ini adalah untuk memetakan aktivitas pengelolaan sampah oleh berbagai elemen di Kabupaten Garut, memetakan persepsi masing-masing elemen terhadap permasalahan sampah serta untuk memetakan isu-isu strategis yang bisa diusulkan sebagai langkahlangkah solutif untuk menyelesaikan permasalahan sampah yang ada di Kabupaten Garut. Hasil dari FGD ini diharapkan dapat dikembangkan menjadi Perda, agar langkah-langkah solutif yang akan dilakukan lebih bisa diimplementasikan hingga ke tingkat lingkungan yang paling dekat dengan warga.

\section{Tinjauan Kepustakaan}

\section{Kebijakan Mengenai Pengelolaan Sampah di Kabupaten Garut}

Kebijakan pengelolaan limbah padat telah menjadi prioritas di banyak negara dan kinerjanya telah menjadi tolok ukur keberlanjutan untuk negara-negara tertentu serta sebagai salah satu indikator penting untuk menilai indeks kualitas hidup yang dikembangkan oleh United Nations Human Settlements Programme (UN-Habitat) (Wee \& Abas, 2016). Kebijakan, legislasi, dan peraturan pengelolaan limbah padat adalah pendekatan utama yang dilakukan oleh pemerintah untuk mengendalikan dan memengaruhi praktik pengelolaan limbah (Abas \& Wee, 2016).

Praktik tradisional, yang masih diterapkan di banyak negara dalam mengatasi masalah limbah padat secara parsial, yaitu mengenai pengelolaan sistem yang ada, pabrik pengolahan, dan pembuangan akhir (Guerrero et al., 2013). Sebaliknya, Rencana Pengelolaan Sampah Terpadu, yang diterapkan di beberapa negara maju, mempertimbangkan seluruh siklus hidup limbah dari pengumpulan dan transportasi hingga rehabilitasi lokasi pembuangan.

Pengembangan Pengelolaan Sampah Terpadu atau Integrated Solid Waste Management (ISWM) didasarkan pada (Yadav, 2015):

a. Integrasi semua elemen siklus hidup limbah padat berdasarkan pada proses 3R (Reduce, Reuse dan Recycle);

b. Integrasi aspek teknis, lingkungan, sosial, keuangan, kelembagaan, dan politik untuk menjamin keberlanjutan sistem; dan

c. Partisipasi aktif semua pemangku kepentingan publik, swasta, dan masyarakat dalam konsepsi dan perencanaan proses dan solusi.

Berdasarkan arahan dari Kementrian Lingkungan Hidup Republik Indonesia (KLH, 2014), pengolahan sampah terbaik adalah jika sudah ada dalam tahapan pencegahan, sedangkan pembuangan sampah melalui TPA yang masih dilakukan banyak daerah adalah tipe pengolahan yang paling dasar. Adapun hirarki pengolahan sampah tersebut disajikan pada Gambar 1. 


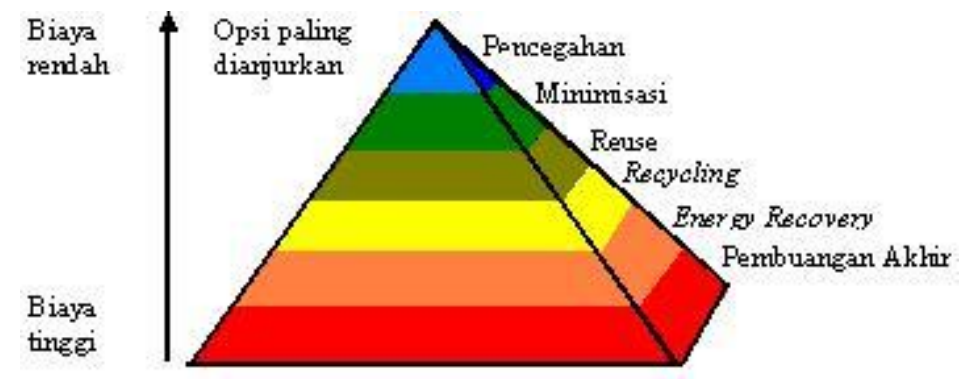

Gambar 1. Hirarki Pengolahan Sampah (KLH, 2014)

Adapun dasar hukum mengenai pengolahan sampah di Indonesia khususnya di Kabupaten Garut antara lain:

a. Undang-undang Republik Indonesia Nomor 18 Tahun 2008 Tentang Pengelolaan Sampah;

b. Peraturan Pemerintah No. 81 Tahun 2012 Tentang Pengelolaan Sampah Rumah Tangga dan Sampah Sejenis Sampah Rumah Tangga;

c. Peraturan Menteri Lingkungan Hidup Republik Indonesia Nomor 13 Tahun 2012 Tentang Pedoman Pelaksanaan Reduce, Reuse dan Recycle Melalui Bank Sampah;

d. Perda No. 4 Tahun 2014 Tentang Pengelolaan Sampah Rumah Tangga dan Sampah Sejenis Sampah Rumah Tangga;

e. Perda No. 18 Tahun 2017 Tentang Perubahan atas peraturan nomer 12 tahun 2015 tentang ketertiban, kebersihan dan keindahan.

Persoalan sampah kota sangat penting karena berkaitan langsung dengan kesehatan masyarakat dan ekonomi sehingga pengelolaannya membutuhkan konvergensi multidisiplin antara teknologi atau solusi rekayasa dan desain kebijakan publik, dengan mempertimbangkan faktor sosial-ekonomi (Chalhoub, 2018). Penelitian ini menindaklanjuti prinsip-prinsip ISMW dalam pengelolaan sampah di perkotaan untuk selanjutnya bisa mengembangkan dasar hukum pengelolaan sampah di Kabupaten Garut.

\section{Kolaborasi Stakeholder dalam Pengelolaan Sampah}

Menurut Salsabila dan Santoso (2018), stakeholder adalah kelompok atau individu yang dukungannya diperlukan demi kesejahteraan dan kelangsungan hidup suatu organisasi atau negara. Sedangkan menurut Hisam (2016), stakeholder ialah suatu masyarakat, kelompok, komunitas ataupun individu manusia yang memiliki hubungan dan kepentingan terhadap suatau organisasi atau perusahaan.

Kategori stakeholder menurut yang dikembangkan diberi label sebagai investor, kontributor, pengamat dan stakeholder pengguna akhir (McGrath \& Whitty, 2017). Berdasarkan tingkat kepentingannya, stakeholder dibagi menjadi tiga kelompok yaitu (Thijssens et al., 2015):

a. Stakeholder primer; Stakeholder primer merupakan stakeholder yang terkena dampak secara langsung baik dampak positif maupun dampak 
negatif dari suatu rencana serta mempunyai kaitan kepentingan langsung dengan kegiatan tersebut. Stakeholder yang memiliki pengaruh dan kepentingan dikatakan sebagai stakeholder primer dan harus dilibatkan penuh dalam tahapan-tahapan kegiatan.

b. Stakeholder Kunci; Stakeholder kunci adalah mereka yang memiliki kewenangan legal dalam hal pengambilan keputusan.

c. Stakeholder sekunder atau pendukung; Stakeholder pendukung merupakan stakeholder yang tidak memiliki kepentingan langsung terhadap suatu rencana tetapi memiliki kepedulian yang besar terhadap proses pengembangan.

Dalam program pembangunan, stakeholder diklasifikasikan berdasarkan peranannya, antara lain (Benn et al., 2016):

a. Pembuat kebijakan yaitu stakeholder yang berperan sebagai pengambil keputusan dan penentu suatu kebijakan;

b. Koordinator yaitu stakeholder yang berperan mengkoordinasikan stakeholder lain yang terlibat;

c. Fasilitator yaitu stakeholder sebagai fasilitator yang berperan menfasilitasi dan mencukupi apa yang dibutuhkan kelompok sasaran;

d. Implementer yaitu stakeholder pelaksana kebijakan yang di dalamnya termasuk kelompok sasaran;

e. Akselerator yaitu stakeholder yang berperan mempercepat dan memberikan kontribusi agar suatu program dapat berjalan sesuai sasaran atau bahkan lebih cepat waktu pencapaiannya.

Inovasi sosial membawa keberlanjutan yang dianggap sebagai paradigma baru bagi pengembangan dimana kolaborasi lintas sektor antara aktor yang berbeda diperlukan, terutama dalam model penta heliks (Vasconcelos \& Nguyen, 2018). Terdapat beberapa model penta helix yang populer dalam teori stakeholders, Pricewaterhousecoopers (2005) menyatakan bahwa yang dimaksud dengan penta helix adalah pemerintah kota, universitas, swasta, asosiasi nirlaba, dan warga negara yang antusias. Sedangkan Calzada (2016), mengungkapkan 5 aktor termasuk penta helix adalah sektor publik dan swasta, akademisi, masyarakat sipil, dan pengusaha sosial, dimana peran sentral dalam kolaborasi diambil secara kaku oleh pengusaha sosial. Berbeda dengan Edvik \& Björk (2016) yang menekankan bahwa peran sentral bisa secara fleksible baik oleh akademisi, administrasi publik, bisnis, warga negara (pengusaha sosial) maupun sektor ketiga. Di Indonesia, istilah penta helix banyak digunakan untuk merujuk kepada akademisi (academics), bisnis (business), komunitas (community), pemerintah (government) dan media yang populer dengan istilah ABCGM (Muhyi et al., 2017; Yuningsih et al., 2019; Kania et al., 2020).

Kolaborasi penta helix dalam pengendalian lingkungan sudah dilakukan di Indonesia (Amrial et al., 2017). Sebelumnya kolaborasi triple helix dalam pengolahan sampah sudah diimplementasikan Rosenlund et al. (2017), hasilnya adalah konsep kolaborasi masih mempunyai kendala, dimana solusi yang dihasilkan perlu diberikan pembatas batas dan disediakan arena umum untuk berdailog. Namun, meski masih banyak kendala, Anttonen et al. (2018) mendorong 
agar pemerintah menerapkan triple helix untuk diterapkan pada kebijakan inovasi limbah agar tercapat perubahan yang sistemik. Penelitian ini mengadopsi temuan Rosenlund et al. (2017); Anttonen et al. (2018); dan Amrial et al., (2017), yang mengusung konsep kolaborasi elemen pembangunan untuk mengatasi persoalan lingkungan terutama pengolahan sampah.

\section{Metode Penelitian}

Penelitian ini menggunakan metode kualitatif dengan pendekatan focus group discussion (FGD) dimana setiap elemen dapat menyampaikan apa yang telah dilakukan dalam pengelolaan sampah, serta bagaimana persepsinya tentang masalah sampah dan apa solusi yang diberikan untuk menyelesaikan masalah sampah, sehingga masing-masing elemen dapat saling mengetahui apa yang disampaikan elemen lainnya. Sedangkan menurut tujuanya penelitian ini menggunakan penelitian exploratif dan pendekatan penelitianya menggunakan longitudinal dengan taraf penelitianya yaitu penelitian inferensial. Sumber data yang lain digunakan adalah studi dokumentasi yang berasal dari laporan kegiatan suatu instansi maupun berasal dari internet.

Observasi dan partisipasi aktif dilakukan peneliti selama kegiatan FGD berlangsung. FGD dilaksanakan pada tanggal 24 Oktober 2019, berlokasi di Hotel Fave Garut. FGD dihadiri 28 Peserta dan dilaksanakan selama 6 jam. Data selanjutnya dibuat transkrip dan dianalisis menggunakan teknik analisis reduksi data. Triangulasi sumber dilakukan dengan cara mengkonfirmasi temuan pada ketua penyelenggara kegiatan sekaligus inisiator FGD.

\section{Hasil dan Pembahasan}

\section{Pemetaan Aktivitas Pengelolaan Sampah dan Persepsi terhadap Masalah Sampah oleh Elemen Masyarakat di Kabupaten Garut}

Dalam kegiatan FGD yang dilakukan di Fave Hotel Garut dihadiri oleh 5 elemen berjumlah 28 kelompok, yaitu Akademisi diwakili oleh Universitas Garut (UNIGA) yang terdiri dari (FEKON, FISIP dan FAPERTA), Sekolah Tinggi Teknologi Garut (STTG) dan Pondok Pesantren Al-Falah Biru (Jumlah 3). Perusahaan yang diwakili oleh BUMDES Cidatar, CV. Priangan Central Plastindo, BUMDES Ngamplang, Bank Sampah Garut, Bank Sampah Ciledug, Bank Sampah Hade Jaya, BUMDES Mekargalih (Jumlah 7). Komunitas yang diwakili oleh PKK Kecamatan Tarogong Kidul, The Creative Institute, Komunitas Sedekah Sampah (SESA), LKP Holistica Institute, Penggiat Lingkungan, Komunitas konservasi Garut (Jumlah 6). Pemerintah yang diwakili oleh Dinas Lingkungan Hidup (DLH), Dinas Pendidikan, Badan Kesatuan Bangsa dan Politik (Bakesbangpol), Dinas Pemberdayaan Masyarakat Desa (DPMD), Disparbud (Dinas Pariwisata dan Kebudayaan), Desperindag (Dinas Perindustrian dan Perdagangan), Dinas Pekerjaan Umum dan Perumhan Rakyat (PUPR), Badan Perencanaan dan Pembangunan Daerah (BAPPEDA), Desa Cidatar, Desa Kersamanek (Jumlah 10). Media diwakili oleh Internet Marketer dan Klippa.com (Jumlah 2). Akan tetapi, dari 28 kelompok yang hadir, hanya 19 kelompok aktif menyampaikan persepsi dan usulan solusi. 


\section{Isu-isu strategis dalam pengelolaan untuk sampah di Kabupaten Garut}

\section{a. Teknologi}

Ada 11 isu utama teknologi yang disampaikan oleh peserta dalam FGD. Lima isu berasal dari elemen pengusahan, 4 isu berasal dari elemen komunitas, dan 2 isu berasal dari pemerintah. Bank Sampah Hade Jaya yang berada di bawah CV. Priangan Central Plastindo sudah memiliki teknologi pengolahan daur ulang plastik menjadi biji plastik namun ada beberapa jenis plastik yang belum bisa didaur ulang, sehingga perlu mendatangkan mesin baru dari China. Biji plastik bukan hal baru di Indonesia, karena bisnis biji plastic cukup menjanjikan. Harga jualnya tinggi karena bisa dibuat menjadi produk daur ulang yang lebih bernilai (Chandara et al., 2015). Sedangkan Bank Sampah Garut menyampaikan sudah mempunyai tiga jenis teknologi pengolahan sampah terpadu (TPST) untuk di perumahan. Keefektifan TPST di beberapa daerah di Indonesia bergantung pada beberapa faktor, selain kesadaran warga, kelembagaan kerap menjadi kendala kelancaran program (Ilham, 2010).

PKK Tarogong Kidul juga sudah mempunyai teknologi pencacah sampah yang berfungsi mengurangi jumlah timbulan sampah. Meski mengaku bahwa efektif untuk segala jenis sampah, tetapi masih perlu dilakukan uji kehandalan mesin yang dibuat (Syamsiro et al., 2016) sebelum diperbanyak ke berbagai desa di Kecamatan Tarogong Kidul. Selanjutnya Sukirno (Penggiat Lingkungan) mempunyai teknologi pengolahan sampah plastik menjadi paving block. Pengolahan sampah menjadi paving block memang cukup populer di beberapa kelompok pengolahan sampah di Garut, namun kendala teknologi, uji produk dan pemasaran produk masih belum bisa menjanjikan untuk produk ini (Agyeman et al., 2019).

Karang Taruna Desa Ngamplang mempunyai teknologi sampah plastik yang diolah menjadi solar. Pengolahan menjadi produk sejenis seperti petrol, kerosene, dan solar juga memang kerap dilakukan di beberapa negara berkembang (Khot \& Basavarajappa, 2017). DPMD mempunyai bidang yang menangani teknologi tepat guna (TTG), salah satu programnya mengadakan perlombaan TTG, diantara pesertanya ada teknologi pengolahan sampah. Peran Disperindag dalam distribusi teknologi adalah dengan memberikan mesin ke pabrik, salah satunya pabrik yang mengolah plastik jadi sedotan.

Teknologi pengolahan sampah sangat dibutuhkan karena akan menyederhanakan pengolahan dan memangkas biaya produksi ditengah tingginya permintaan bahan baku dari olahan sampah, sebagaimana Sucipto (2009) menyatakan Peluang usaha di bidang daur ulang sampah sangat menjanjikan, harga bahan baku kemasan semakin tinggi terutama bijih plastik, permintaan sangat tinggi dari negara industri seperti Cina. Teknologi yang tepat juga diperlukan di Tempat Pemrosesan Akhir (TPA). Menurut Chamdra et al. (2015) ada empat alternatif teknologi yaitu insinerator, sanitary landfill, pengomposan dan daur ulang tetapi masih perlu dikembangkannya teknologi lain yang lebih baik.

\section{b. Pendidikan}

Ada 21 isu utama yang disampaikan pesera dalam FGD dimana 7 isu berasal dari kalangan pengusaha, 1 dari akademisi, 7 isu dari komunitas dan 6 isu dari pemerintah. Sebagai wujud dari kepedulian kampus terhadap lingkungan, Fisip 
UNIGA menyampaikan bahwa isu sampah telah menjadi bagian dari roadmap penelitian dosen periode 2018-2023. Harapannya adalah semakin banyak penelitian bidang administrasi negara yang berfokus pada persoalan lingkungan khususnya sampah di Kabupaten Garut.

Bank Sampah Hade Jaya juga telah melakukan sosialisasi sampah yang mempunyai nilai ekonomi malalui Balai Latihan Kerja (BLK) yang dimilikinya. CV. Priangan Central Plastindo menyampaikan perlu adanya edukasi terhadap masyarakat, pihaknya baru memberikan pelatihan di 6 Kelurahan di Kecamatan Garut Kota. Bank Sampah Garut juga mengaku telah melakukan edukasi cara pemilahan sampah dan edukasi 34 jenis sampah di 50 titik sekolah SMP dan SMA, memberikan edukasi limbah sampah plastik menjadi seni kriya menggunakan sistem laminasi.

Holistika Institute hingga saat ini aktif melakukan pemberdayaan masyarakat di Garut dengan konsep bukan hanya memberikan edukasi tetapi hingga bisa berdampak para perubahan perilaku warga. Gerakan peduli lingkungan melakukan edukasi kepada masyarakat untuk meningkatkan kesadaran dalam kebersihan lingkungan. Karang Taruna Desa Ngamplang melakukan sosialisasi dengan membagikan 2 kantong plastik ke setiap rumah untuk sampah organik dan anorganik.

Sekda menyampaikan agar seluruh kegiatan baik dari pemerintah, akademisi dll harus dikemas secara edukasi melalui media massa, harus memaksimalkan peran media yang bisa merubah pola pikir masyarakat. Disperindag memasukan persoalan sampah pada setiap draf pembinaan. Disparbud melakukan sosialisasi tentang sampah dan harus menumbuhkan kesadaran di lingkungan sekolah serta merubah mindset masyarakat tentang sampah agar tumbuh kebiasaan dan kesadaran.

Dari temuan dihasilkan bahwa sudah banyak kelompok yang mencoba memberikan edukasi kepada masyarakat mengenai pentingnya menjaga kebersihan dan kesehatan lingkungan melalui cara pengelolaan sampah rumah tangga yang benar. Namun, hasil evaluasi menunjukkan bahwa ternyata hasilnya belum berdampak dan belum mampu merubah perilaku warga. Dibutuhkan suatu pemikiran dari elemen pembangunan untuk merumuskan pola edukasi yang sesuai dan bisa diterapkan oleh masyarakat Garut.

\section{c. Ekonomi}

Terdapat 8 isu yang disampaikan peserta FGD dimana 5 diantaranya berasal dari bisnis, 2 isu dari komunitas dan 1 isu dari pemerintah. Bank Sampah Hade Jaya melakukan penjualan sampah plastik yang belum dapat diolah ke pengepul, melakukan sosialisasi bahwa sampah mempunyai nilai ekonomi, memasarkan produk biji plastik ke Tasik dan Tangerang. CV. Priangan Central Plastindo menerima sampah plastik untuk diolah, menyampaikan bahwa sampah bisa menghasilkan dan memiliki nilai ekonomi, ada 400 perusahaan raksasa yang membutuhkan bahan baku dari plastik.

Holistika Institute menyampaikan bahwa ada paradigma yang mengganggap sampah sebagai komoditas dan mempunyai nilai ekonomi. Disperindag menyampaikan bahwa harus ada manajemen sampah berkelanjutan yang 
bekerjasama dengan lembaga ekonomi tingkat desa, mengangkat produk Garut seperti kerajinan dari limbah kayu ke Dekranasda (Dewan Kerajinan Nasional Daerah) untuk dipamerkan sebagai alternatif pemasaran. Media pameran memang dianggap lebih efektif dibandingkan dengan media promosi tradisional lain seperti pamflet atau brosur penjualan (Sucahya \& Surahman, 2017). Informasi, sosialisasi, perencanaan yang baik dan kebijakan yang mendukung maka persoalan sampah akan berubah menjadi potensi ekonomi yang prospektif bagi warga (Nugraha et al., 2007; Ramadhani, 2014).

\section{d. Kelembagaan}

Terdapat 6 isu yang disampaikan peserta FGD mengenai kelembagaan, 3 diantaranya berasal dari pengusaha, 2 dari komunitas dan 1 dari pemerintah. Bank Sampah Hade Jaya sudah berbentuk yayasan dan ada BLK, membuat unit-unit Bank Sampah di tiap RW di Kecamatan Samarang. CV. Priangan Central Plastindo menyampaikan perlunya membangun sistem yang baik untuk hasil yang lebih baik. Sedangkan dari komunitas The Creative Institute menyampaikan belum bisa seperti Bank Sampah umumnya, tetapi konsepnya lebih dimodifikasi dengan program bernama BURUKEN (Bumi Runtah Token). Dari sisi pemerintah, Disperindag menyampaikan harus ada manajemen berkelanjutan yang melibatkan lembaga ekonomi tingkat Desa.

Bentuk lembaga yang ideal untuk pengelolaan sampah pernah dipublikasikan Qodriyatun (2015) yang menyarakan bahwa sebaiknya dibentuk Badan Layanan Umum Daerah (BLUD) sebagai operator dan dinas berperan pada tingkat regulator. Garut belum memiliki lembaga lain yang mengelola sampah selain DLH, dan DLH saat ini perannya lebih banyak pada penyediaan infrastruktur sampah seperti tempat sampah, iniserator dan lain sebagainya, sehingga solusi mengenai kelembagaan masih perlu didiskusikan oleh Gerakan Garut Bebas Sampah.

\section{e. Kebijakan}

Terdapat 8 isu yang disampaikan peserta pada FGD dimana 2 isu berasal dari pengusaha, 3 isu dari komunitas, 2 isu dari pemerintah dan 1 isu dari media. CV Priangan Central Plastindo menyampaikan TPA terbuka harus sudah dihentikan dan Garut harus sudah memulai TPA tertutup. Holistika Institute berpendapat bahwa regulasi apapun yang diberlakukan pemerintah perlu dukungan multi elemen untuk implementasinya. Klippa. Com menekankan aspek regulasi seperti adanya aturan bupati atau perda yang mengatur pengelolaan sampah yang dikaitkan dengan Dana Desa. Contohnya sudah diinsiasi Karang Taruna Desa Ngamplang mengatakan bahwa dukungan desa terhadap pengelolaan sampah diwujudkan dari anggaran Rp. 150 juta untuk membuat Imah Runtah (Rumah Pengolahan Sampah).

Menanggapi saran dari pengusaha dan komunitas, Disperindag menyampaikan bahwa dalam Perda tahun 2014 tentang sampah masih ada kebijakan yang belum ada turunannya. Bappeda selanjutnya menyampaikan bahwa pemerintah sedang membuat kebijakan strategis dalam Rencana Pembangunan Jangka Menengah Daerah (RPJMD) berdasarkan janji bupati tentang Garut bebas sampah. Mulasari, Husodo et al. (2014) mengungkapkan jika kebijakan pemerintah 
mengenai pengelolaan sampah domestic akan berjalan dengan optimal jika disertai mekanisme monitoring dan evaluasi yang baik dari pihak pemerintah daerah.

\section{f. Koordinasi}

Terdapat 12 isu yang disampaikan peserta FGD, 1 isu berasal dari akademisi, 3 isu dari pengusaha, 5 isu dari komunitas dan 3 isu dari pemerintah. Universitas Garut dalam hal ini sangat berperan dalam upaya memberikan ruang bagi seluruh elemen penggiat, pengelola, dan pengusaha sampah untuk saling memberikan informasi, sekaligus berkoordinasi di masa depan melalui aktivitas FGD. Koordinasi parsial sudah dilakukan oleh Bank Sampah Hade Jaya terhadap sejumlah ibu-ibu PKH, dinas terkait hingga wakil Gubernur. CV. Priangan Central Plastindo menyampaikan harus ada komitmen dari semua pihak untuk membangun sistem koordinasi yang baik dan disepakati bersama.

Holistika Institute menyampaikan perlu adanya intervensi dari dinas terkait untuk memberdayakan produk masyarakat dari sampah, sehingga penggiat sampah tetap bisa eksis, dan semua elemen harus saling mendukung. The Creative Institute menyampaikan harus ada sinergitas untuk merubah pola pikir masyarakat, saat ini pihaknya telah berkolaborasi dengan Universitas Indonesia dan Holistika Institute dalam melakukan edukasi terhadap masyarakat.

Dari sisi pemerintah, DPMD menyampaikan harus ada sinergitas Satuan Kerja Perangkat Daerah (SKPD) lintas sektor. Yang sebetulnya pemerintah melalui Disperindag telah melakukan FGD dengan rekan-rekan fungsional, namun masih belum berkoordinasi dengan pihak lain. Bappeda juga telah bekerjasama dengan DLH dan BPBD terkait penanganan kekumuhan dan masih perlu menjalin koordinasi dengan elemen pendukung lainnya.

Dari temuan di atas dapat dilihat bahwa koordinasi yang dilakukan oleh masing-masing elemen atau antar elemen masih bersifat parsial. FGD yang diselenggarakan oleh pihak UNIGA dianggap sebagai terobosan koordinasi pengolahan sampah di Kabupaten Garut dan perlu dilanjutkan. Semua elemen berharap bahwa FGD akan bisa rutin dilaksanakan sebagai media koordinasi Gerakan Garut Bebas Sampah. Partisipasi masyarakat mutlak diperlukan yang bisa digerakan dari mulai tingkat RT/ RW setempat (Sulistiyorini et al., 2016). Namun, sebelum mengharapkan partisipasi masyarakat, koordinasi dan kebijakan di level pemerintah perlu ditetapkan terlebih dahulu (Arief, 2013). Pembangunan infrastruktur yang memadai juga perlu dilakukan pemerintah yang disertai dengan komunikasi dan kolaborasi antara dinas terkait. Kinerja strategi desentralisasi harus terus dipantau untuk memastikan bahwa administrator lokal bertanggung jawab dan menjalankan fungsinya dengan baik (Massoud et al., 2019). Rangkuman persepsi dan isu strategis yang diusulkan untuk FGD berikutnya disajikan pada Gambar 2. 


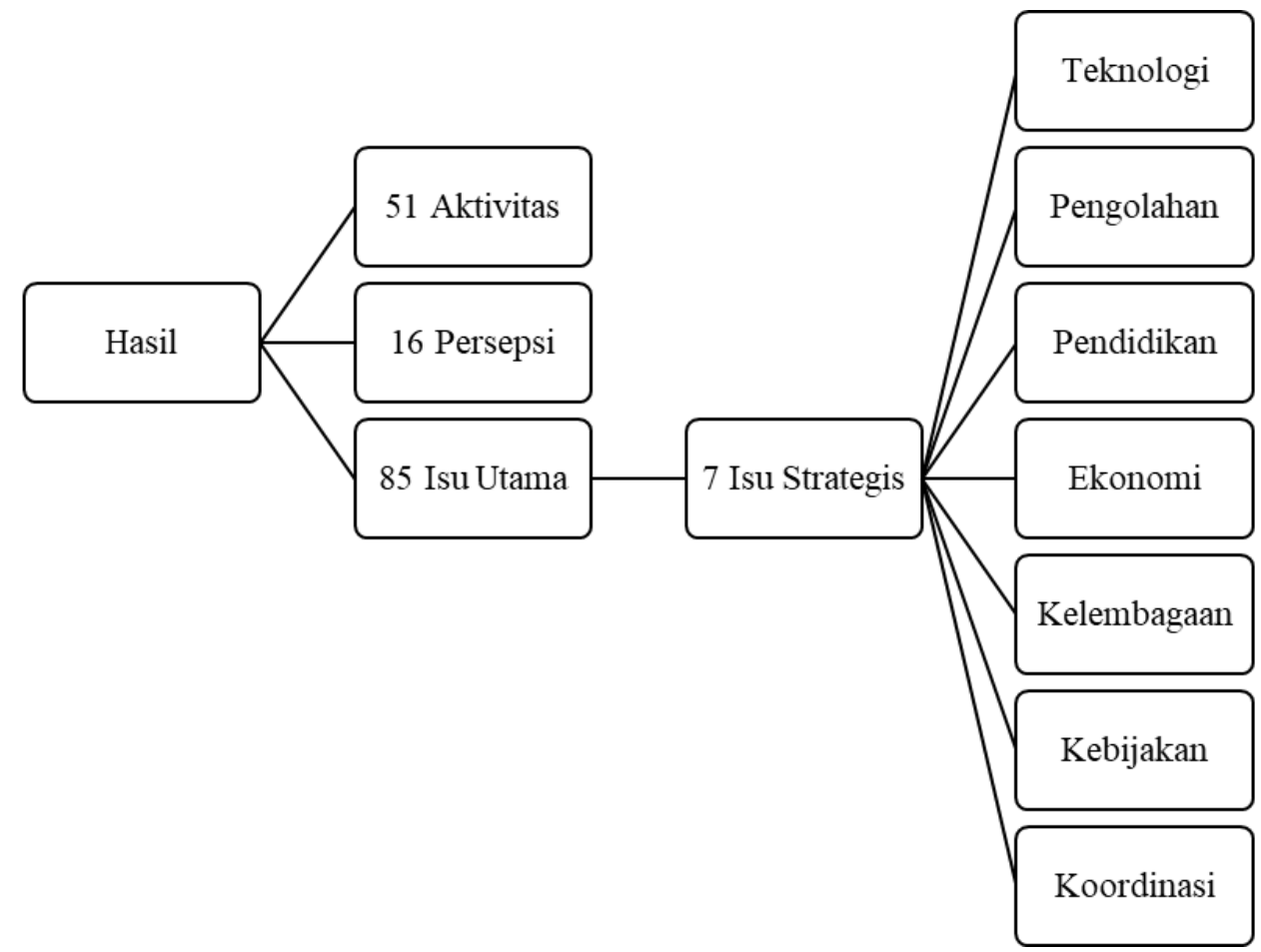

Gambar 2. Rangkuman Peta Persepsi Hasil FGD

\section{Penutup}

Berdasarkan pembahasan diatas dapat diambil kesimpulan dari 19 grup elemen pentahelix yang berbicara dalam FGD ada 51 aktivitas yang telah dilakukan dalam upaya penyelesaian masalah sampah di Kabupaten Garut, terdapat 16 persepsi tentang masalah sampah dan 7 isu strategis yang dapat diusulkan sebagai langkah solutif pengelolaan sampah di Kabupaten Garut yaitu teknologi, pengolahan, pendidikan, ekonomi, kelembagaan, kebijakan dan koordinasi.

Terima kasih kami sampaikan kepada Fakultas Ilmu Sosial dan Ilmu Politik, Universitas Garut atas kesempatannya mengikuti kegiatan FGD yang diinisiasi oleh membernya yaitu Dr. Ikeu Kania., MSi. Juga terima kasih kami sampaikan pada seluruh peserta FGD penta helix yang berkenan untuk didokumentasikan terutama pada tim Holistika Institute yang kemudian memfasilitasi media komunikasi Gerakan Garut Bebas Sampah di media WhatsApp.

\section{DAFTAR KEPUSTAKAAN}

Abas, M. A., \& Wee, S. T. (2016). Municipal Solid Waste Management in Malaysia: An Insight Towards Sustainability. SSRN Electronic Journal, 192206. https://doi.org/10.2139/ssrn.2714755

Agyeman, S., Obeng-Ahenkora, N. K., Assiamah, S., \& Twumasi, G. (2019). Exploiting recycled plastic waste as an alternative binder for paving blocks 
production. Case Studies in Construction Materials, 11, 1-8. https://doi.org/10.1016/j.cscm.2019.e00246

Amrial, A., Muhamad, E., \& Adrian, A. M. (2017). Penta helix model: A sustainable development solution through the industrial sector. $14^{\text {th }}$ Hokkaido Indonesian Student Association Scientific Meeting. HISAS 14: 152-156

Anttonen, M., Lammi, M., Mykkänen, J., \& Repo, P. (2018). Circular economy in the Triple Helix of innovation systems. Sustainability (Switzerland), 10 (8), 214. https://doi.org/10.3390/su10082646

Aprizal Ramadhani. (2014). Studi Pengelolaan Sampah Pasar di Kota Medan. Teknik Sipil Universitas Sumatera Utara.

Arief, S. (2013). Pengelolaan Sampah Malang Raya Menuju Pengelolaan Sampah Terpadu Yang Berbasis Partisipasi Masyarakat. Jurnal Humanity, 9 (1), 195208.

Benn, S., Abratt, R., \& O'Leary, B. (2016). Defining and identifying stakeholders: Views from management and stakeholders. South African Journal of Business Management, 47 (2), 1-11. https://doi.org/10.4102/sajbm.v47i2.55

Bunyamin, Z., Efendi, R., Andayani, N. N., Penelitian, B., \& Serealia, T. (2013). Pemanfaatan Limbah Jagung Untuk Industri Pakan Ternak. Seminar Nasional Inovasi Teknologi Pertanian, 153-156.

Calzada, I. (2016). (Un)Plugging Smart Cities with Urban Transformations: Towards Multi-Stakeholder City-Regional Complex Urbanity? URBS. Revista de Estudios Urbanos y Ciencias Sociales.

Chalhoub, M. S. (2018). Public policy and technology choices for municipal solid waste management a recent case in Lebanon. Cogent Environmental Science, 4(1). https://doi.org/10.1080/23311843.2018.1529853

Chamdra, S., Pellokila, M. R., \& Ramang, R. (2015). Analisis Teknologi Pengolahan Sampah Di Kupang Dengan Proses Hirarki Analitik Dan Metode Valuasi Kontingensi (Analysis of Waste Treatment Technology in Kupang with Analytic Hierarchy Process and Contingent Valuation Method). Jurnal Manusia Dan Lingkungan, 22(3), 350-356. https://doi.org/ 10.22146/jml. 18761

Chandara, H., Sunjoto, S., \& Sarto, S. (2015). Plastic Recyling In Indonesia By Converting Plastic Wastes (Pet, Hdpe, Ldpe, And Pp) Into Plastic Pellets. ASEAN Journal of Systems Engineering, 3(2), 65-72.

Dewi Nurdiyanti, Utami, A. S., Bastian, N., \& Johan. (2017). Pemanfaatan Limbah Organik Pasar Sebagai Bahan Pupuk. Universitas Muhammadiyah Cirebon.

Djuwendah, E., Hapsari, H., Renaldy, E., \& Sadah, Z. (2013). Strategi Pengembangan Daerah Tertinggal Di Kabupaten Garut. Sosiohumaniora, 15(2), 211-221. https://doi.org/10.24198/sosiohumaniora.v15i2.5744

Edvik, A., \& Björk, F. (2016). Social Change Through Temporary, Short-term 
Intervention. In L. L. Andersen, M. Gawell, \& R. Spear (Eds.), Social Entrepreneurship and Social Enterprises: Nordic Perspectives. New York: Routledge.

Guerrero, L. A., Maas, G., \& Hogland, W. (2013). Solid waste management challenges for cities in developing countries. Waste Management. https://doi.org/10.1016/j.wasman.2012.09.008

Ilham, I. (2010). Efektivitas Sistem Pengolahan Sampah Terpadu (TPST) pada Perumahan Graha Asri Kendari. Unity Jurnal Arsitektur, 1(1), 11-20.

Indonesia, R. (2008). Undang-Undang Nomer 18 Tahun 2008 Tentang Pengelolaan Sampah. Indonesia.

Kania, I., Alamanda, D. T., Pundenswari, P., \& Ramdhani, A. (2020). Waste Management by Garut Youth Movement, Indonesia. TEST Engineering and Management, 82(January-February 2020), 3738-3745.

Khot, M. B., \& Basavarajappa, S. (2017). Plastic Waste Into Fuel Using Pyrolysis Process. International Research Journal of Engineering and Technology, 4(9), 339-342.

KLH. (2014). Kebijakan Pengolahan Sampah dalam Penerapan Teknologi Sumber Energi Alternatif terbarukan.

Liputan6.com. (2019). Kreatif, Sampah di Garut Bisa Ditukar dengan Token Listrik. Www.Liputan6.Com. Retrieved from https://www.liputan6.com/ regional/read/4018395/kreatif-sampah-di-garut-bisa-ditukar-dengan-tokenlistrik

Massoud, M. A., Mokbel, M., Alawieh, S., \& Yassin, N. (2019). Towards improved governance for sustainable solid waste management in Lebanon: Centralised vs decentralised approaches. Waste Management and Research, 37(7). https://doi.org/https://doi.org/10.1177/0734242X19836705

McGrath, S. K., \& Whitty, S. J. (2017). Stakeholder defined. International Journal of Managing Projects in Business. https://doi.org/10.1108/IJMPB-12-20160097

Muhyi, H. A., Chan, A., Sukoco, I., \& Herawaty, T. (2017). The Penta Helix Collaboration Model in Developing Centers of Flagship Industry in Bandung City. Review of Integrative Business and Economics Research, 6 (1), 412-417.

Mulasari, S. A., Husodo, A. H., \& Muhadjir, N. (2014). Kebijakan Pemerintah dalam Pengelolaan Sampah Domestik. Kesmas: National Public Health Journal, 8(8), 404-410. https://doi.org/10.21109/kesmas.v8i8.412

Nugraha, W. D., Suri, D. A., \& Syafrudin, S. (2007). Studi Potensi Pemanfaatan Nilai Ekonomi Sampah Anorganik Melalui Konsep Daur Ulang Dalam Rangka Optimalisasi Pengelolaan Sampah (Studi Kota Magelang). TEKNIK, 28(1), 9-21.

Pojoh, B. (2018). Pembuatan Papan Laminating Dari Tulangan Bambu 
Menggunakan Limbah Plastik Sebagai Bahan Pengisi Dan Perekat. Jurnal Penelitian Teknologi Industri. https://doi.org/10.33749/jpti.v8i2.2164

Pricewaterhousecoopers. (2005). Cities of the future: Global competition, local leadership. Access by Internet: Www. Pwcglobal. Com/Extweb/ .... https://doi.org/10.1177/0096144203029004007

Qodriyatun, S. N. (2015). Bentuk Lembaga yang Ideal Dalam Pengelolaan Sampah di Daerah (Studi di kota Makang dan Kabupaten Gianyar). Aspirasi, 6(1), 1326.

Rosenlund, J., Rosell, E., \& Hogland, W. (2017). Overcoming the triple helix boundaries in an environmental research collaboration. Science and Public Policy. https://doi.org/10.1093/scipol/scw045

Salsabila, T. ., \& Santoso, R. (2018). Analisis Stakeholder (Aktor Kebijakan) Dalam Pengembangan Obyek Wisata Cidani Gedongsongo di Kabupaten Semarang. Journal of Public Policy And Management Review, 7 (2). doi:10.14710/jppmr.v7i2.20139

Sucahya, M., \& Surahman, S. (2017). Difusi Inovasi Program Bank Sampah (Model Difusi Inovasi Pemberdayaan Masyarakat dalam Pengelolaan Bank Sampah Alam Lestari di Kota Serang Provinsi Banten). Jurnal Ilmu Komunikasi, 8(1), 63-79.

Sucipto, C. D. (2009). Teknologi Pengolahan Daur Ulang Sampah. In Teknologi Pengolahan Daur Ulang Sampah.

Sulistiyorini, N. R. S., Darwis, R. S., \& Gutama, A. S. (2016). Partisipasi Masyarakat Dalam Pengelolaan Sampah Di Lingkungan Margaluyu Kelurahan Cicurug. Prosiding Penelitian Dan Pengabdian Kepada Masyarakat. https://doi.org/10.24198/jppm.v3i3.13786

Syamsiro, M., Hadiyanto, A. N., \& Mufrodi, Z. (2016). Rancang Bangun Mesin Pencacah Plastik Sebagai Bahan Baku Mesin Pirolisis Skala Komunal. Jurnal Mekanika Dan Sistem Termal (JMST), 1 (2), 43-48.

Thijssens, T., Bollen, L., \& Hassink, H. (2015). Secondary Stakeholder Influence on CSR Disclosure: An Application of Stakeholder Salience Theory. Journal of Business Ethics, 132, 873-891. https://doi.org/10.1007/s10551-015-2623-3

Vasconcelos, C., \& Nguyen, M. H. (2018). Initial conditions for Penta Helix collaboration in social innovation" A case study of ReTuren. Malmo University.

Wee, S. T., \& Abas, M. A. (2016). A Review of the Public Policy for Solid Waste Management in Malaysia: An Insight towards Sustainable Solid Waste Management. Australian Journal of Basic and Appalied Sciences, 10(1), 5864.

Yuningsih, T., Darmi, T., \& Sulandari, S. (2019). Model Pentahelik Dalam Pengembangan Pariwisata Di Kota Semarang. JPSI (Journal of Public Sector Innovations), 3 (2), 84-93. https://doi.org/10.26740/jpsi.v3n2.p84-93 
Yuniva, I., Andriansah, A., \& Maulina, D. J. (2018). Perancangan Sistem Informasi Penjualan Produk Hasil Daur Ulang Sampah Berbasis Website Dengan Pendekatan Metode Waterfall. Jurnal Media Informatika Budidarma, 2(4), 174-178. https://doi.org/10.30865/mib.v2i4.896 